\title{
A new species of Austrarchaea (Araneae: Archaeidae) from Western Australia
}

\author{
Mark S. Harvey \\ Department of Terrestrial Invertebrates, Western Australian Museum, \\ Francis Street, Perth, Western Australia 6000, Australia
}

\begin{abstract}
A new species of Austrarchaea, A. robinsi, is described from the Stirling Range National Park. It most closely resembles the only other named Western Australian archaeid, A. mainae Platnick, in the morphology of the female genitalia, but differs in the lack of abdominal tubercles.
\end{abstract}

\section{INTRODUCTION}

Spiders of the family Archaeidae hold a special place in the minds of many arachnologists (see Forster and Platnick, 1984) - firstly, as the original species were described from fossilised remains in Baltic Amber prior to the discovery of Recent species in Madagascar, and secondly, as indicators of the ancient links between the southern continents, where the Recent fauna is known only from Australia, Madagascar and South Africa. The Australian fauna consists of four named species attributed to the genus Austrarchaea Forster and Platnick: $A$. nodosa (Forster), the type species, from south-eastern Queensland, $A$, daviesae Forster and Platnick from north-eastern Queensland, $A$. hickmani (Butler) from Victoria and New South Wales, and A. mainae Platnick from south-western Australia (Butler, 1929; Forster, 1956; Forster and Platnick, 1984; Platnick, 1991). Main (1995) recorded several juvenile archaeids from two forested localities near Pemberton in southwestern Australia, but the identity of these populations will require the collection and study of adult specimens.

The collection of numerous spiders from the Stirling Range National Park by Sarah Barrett of the Department of Conservation and Land Management in 1996 yielded an adult archaeid which proved to be distinct from all of the previously named species of Austrarchaea. This species is named here.

\section{SYSTEMATICS}

Family Archaeidae

Genus Austrarchaea Forster and Platnick

Austrarchaea robinsi sp. nov.

Figures 1-4

\section{Material Examined}

Holotype

\%, Ellen Peak, Stirling Range National Park, Western Australia, Australia, $34^{\circ} 21^{\prime} 20^{\prime \prime} \mathrm{S}$, $118^{\circ} 19^{\prime} 45^{\prime \prime E}, 28$ May 1996, pitfall traps, S. Barrett (Western Australian Museum T42580).

\section{Diagnosis}

Austrarchaea robinsi differs from A. mainae, A. nodosa and $A$. daviesae by the lack of abdominal tubercles (Figure 1), and from A. hickmani by the presence of seta-bearing tubercles on the lateral and posterior margins of the carapaceal neck (Figure 1), and the presence of a petiolar sclerite which does not fully encircle the petiole. Austrarchaea robinsi appears to be the sister species to $A$. mainae as both possess numerous elongate spermathecae which fan out on either side of the gonopore (Figure 3 ).

\section{Description}

\section{Female (holotype)}

Colour: carapace, chelicerae and sternum

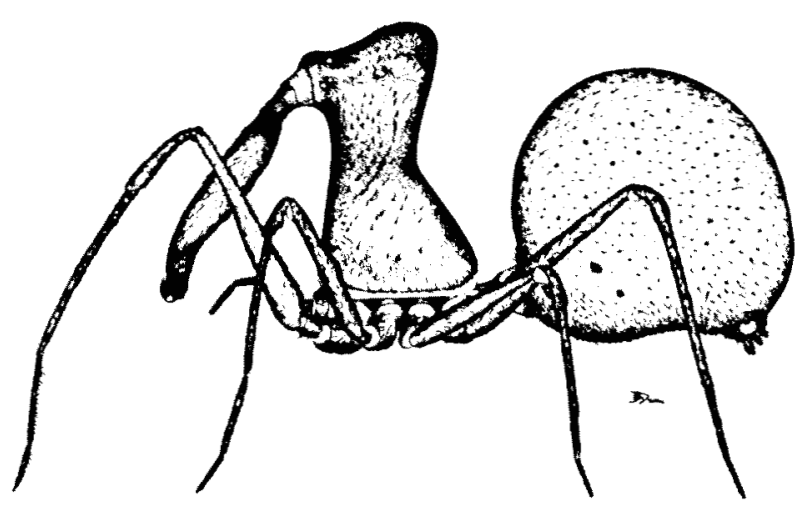

Figure 1 Austrarchaea robinsi sp. nov., holotype $?$, lateral view. 

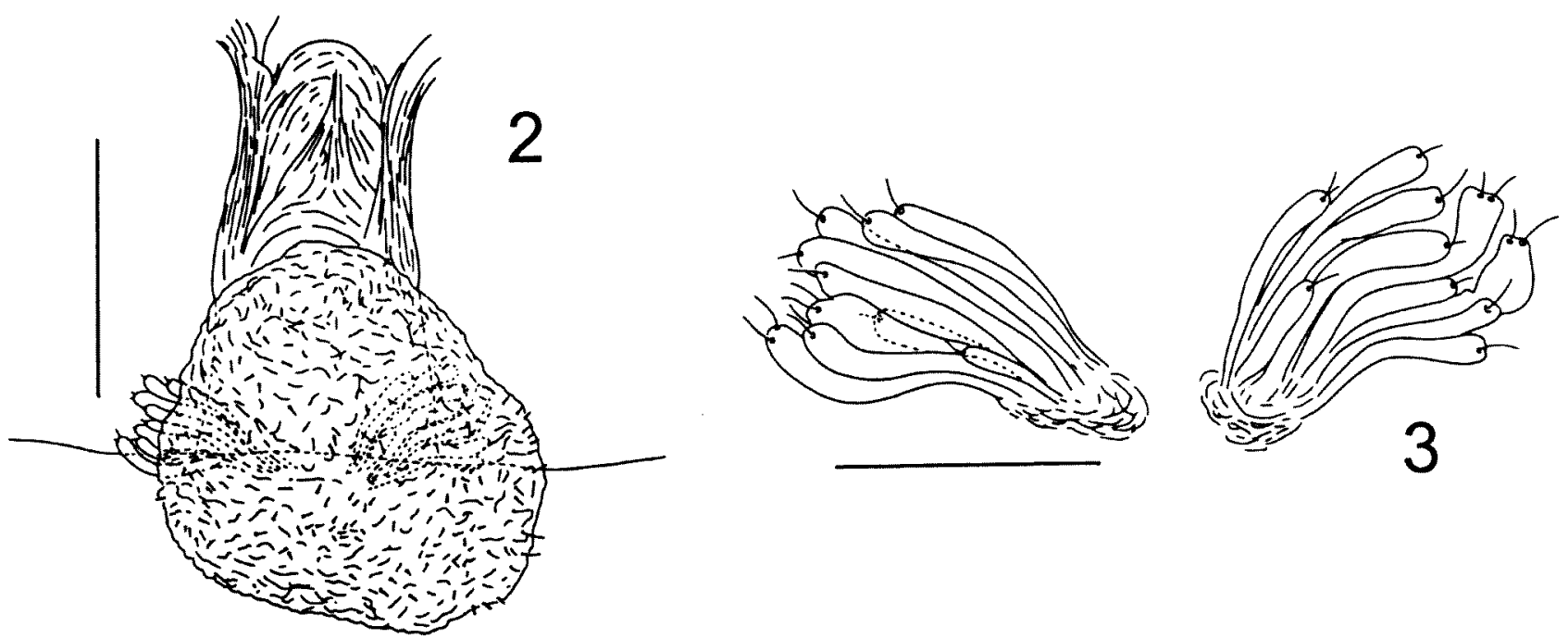

Figures 2-3 Austrarchaea robinsi sp. nov., holotype $\%$, genitalia, dorsal view: 2, entire genitalic region showing anterior and posterior receptacula, and spermathecae; 3 , detail of spermathecae. Scale lines $=0.1 \mathrm{~mm}$.

chestnut-brown, streaked with black markings; legs brown, with dark bands on distal end of femora, patellae, tibiae, and metatarsi; abdomen greyyellow with sclerites all chestnut-brown. Carapace (Figure 1) with numerous white setae, generally anteriorly directed; without dorsal horns; with several rows of seta-bearing tubercles situated mostly on neck, a larger patch of tubercles situated on posterior portion of neck. Eight eyes in 2 rows; AME black, other eyes white; AMEs closer together than PMEs; ALE and PLE nearly contiguous. Chelicerae extremely elongate; without proximal lobe; distal end reflexed posteriorly; three rows of peg teeth, 17 in main row, 3 in anterior row and 1 situated posteriorly, large ridged area (presumptive stridulatory file) on subdistal region of external margin. Sternum with concave anterior margin and rounded posterior margin, lateral margins extending between coxae but not fused or adjoined to carapace. Pedipalp with small tarsal claw. Legs long and slender; formula 1423; femur II, III and, to a lesser extent, IV, with a sub-medial dorsal protuberance; tibiae I-III with 2 trichobothria, 1 subdistal, 1 sub-basal; tibiae IV with 3 trichobothria, 2 sub-basal, 1 sub-distal; metatarsus with 1 sub-distal trichobothrium; all trichobothria associated with darkly pigmented bands on segments; each tarsus with 3 small claws. Abdomen (Figure 1) spherical, without tubercles, cuticle thin with little trace of thickening; sparsely covered with setae which are either black or white; epigastric region with four separate plates, a sub-triangular plate covering genital region, situated between two pulmonary plates, and petiolar sclerite which is only present on ventral portion of abdomen, not encircling petiole; sclerotized ridged plate (presumptive stridulatory file) above petiole; c. 16 small circular sclerites present between epigastric region and spinnerets, with 4 pairs of larger sclerites laterally. Internal genitalia (Figures 2,3) with c. 10 pairs of receptacula arranged in two groups, each receptaculum with thin translucent duct, terminal bulb and 1-2 distal tubules. Six spinnerets; anteriorlateral spinnerets largest, two-segmented; posteriormedian spinnerets very small; posterior-lateral spinnerets short; colulus absent.

Dimensions $(\mathrm{mm})$ : total length (excluding chelicerae) 4.30. Carapace length (measured at base) 1.20 , width 1.10 , height 1.90 . Eye group width 0.87 . Sternum length 0.70 , width 0.44 . Chelicera length 1.96. Pedipalp: femur 0.30 , patella 0.17 , tibia 0.35 , tarsus 0.44 , total 1.26 . Leg I: femur 1.98 , patella 0.83 , tibia 1.62, metatarsus 0.89 , tarsus 0.58 , total 5.90. Leg II: femur 1.40 , patella 0.41 , tibia 1.32 , metatarsus 0.58 , tarsus 0.41 , total 4.12 . Leg III: femur 1.19, patella 0.41, tibia 1.10, metatarsus 0.49 , tarsus 0.40 , total 3.59. Leg IV: femur 1.81 , patella 0.43 , tibia 1.37 , metatarsus 0.68 , tarsus 0.39 , total 4.68 . Abdomen length 2.04 , width 1.79 , height (without spinnerets) 2.42 .

\section{Remarks}

Austrarchaea robinsi shares with $A$. hickmani a lack of abdominal tubercles, but possesses small setabearing tubercles on the carapace which are absent in $A$. hickmani. As noted above, $A$. robinsi appears to represent the sister species of $A$. mainae as both possess numerous elongate spermathecae which fan out on either side of the gonopore (Figure 3, and Platnick, 1991, figure 7), a feature which is not found in any other archaeid, and which is markedly different from the eastern Australian species of Austrarchaea. This may indicate a separate radiation of the genus in Western Australia, based upon a shared ancestor. However, until the identity of the juveniles from the Pemberton region is ascertained, such hypotheses are speculative. 


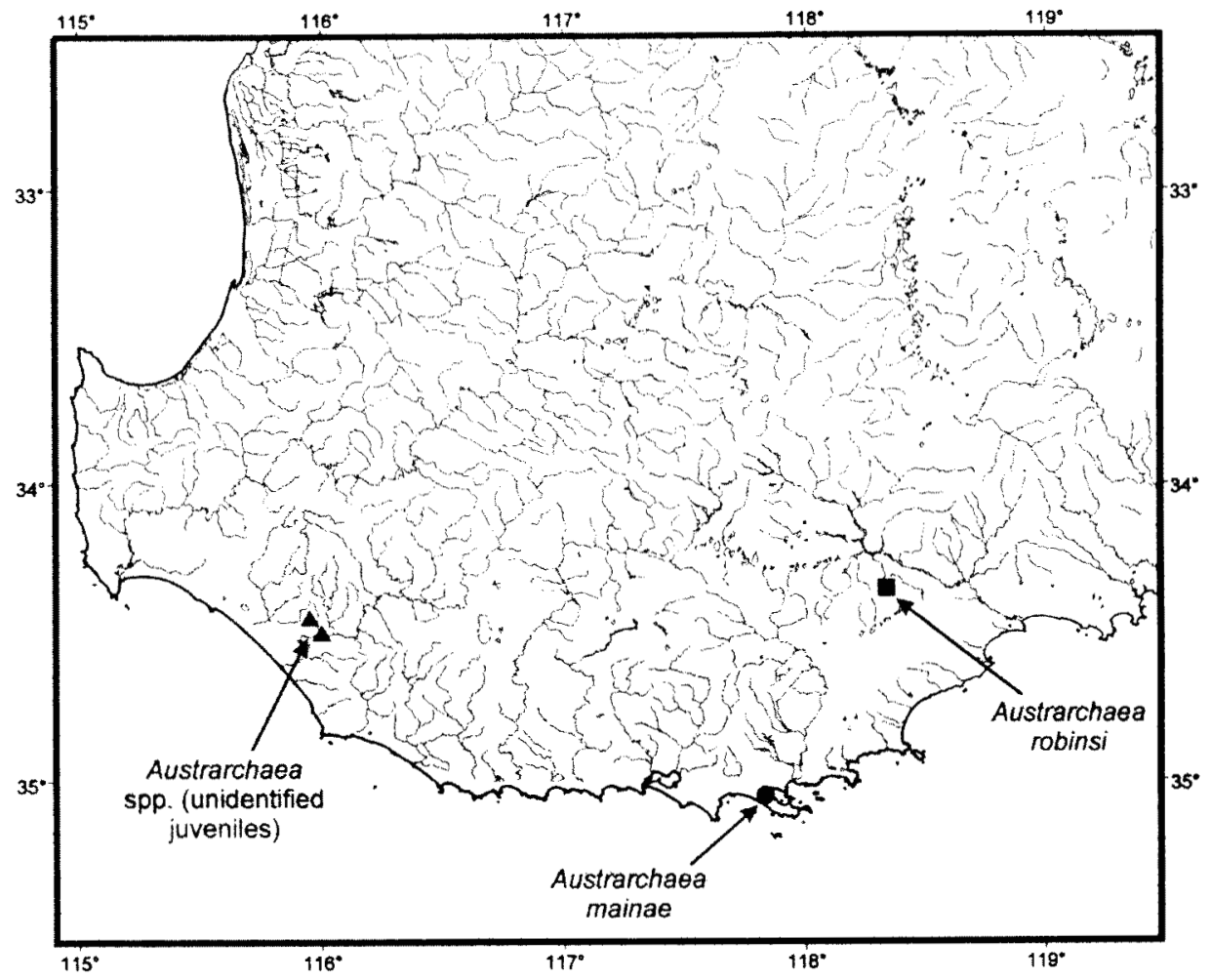

Figure 4 Map showing known distribution of Austrarchaea species in Western Australia: A. mainae, $\Delta$ unidentified juveniles.

The species is currently known from only a single specimen collected in a pitfall trap placed on Ellen Peak in the eastern portion of the Stirling Range (Figure 4). The Stirling Ranges are internationally renowned for their endemic biota, which includes several endemic spiders such as the trapdoor spiders Neohomogona stirlingi Main (Main, 1985) and an undescribed species of Moggridgea (B.Y. Main, personal communication). It is highly likely that Austrarchaea robinsi is also endemic to the Stirling Range where it survives amongst montane heath vegetation on one or more peaks.

\section{Etymology}

This species is named for Western Australian paralympian Noel Robins, the first recipient in the Western Australian Museum's Live Forever program.

\section{ACKNOWLEDGEMENTS}

I am extremely grateful to Sarah Barrett for providing the only known specimen of this interesting species, and to Bradley Durrant for Figure 1.

\section{REFERENCES}

Butler, L.S.G. (1929). Studies in Victorian spiders, No. 1. Proceedings of the Royal Society of Victoria (new series) 42: 41-52.

Forster, R.R. (1956). A new spider of the genus Archaea from Australia. Memoirs of the Queensland Museum 13: 151-154.

Forster, R.R. and Platnick, N.I. (1984). A review of the archaeid spiders and their relatives, with notes on the limits of the superfamily Palpimanoidea (Arachnida, Araneae). Bulletin of the American Museum of Natural History 178: 1-106.

Main, B.Y. (1985). Further studies on the systematics of ctenizid trapdoor spiders: a review of the Australian genera (Araneae: Mygalomorphae: Ctenizidae). Australian Journal of Zoology, Supplementary Series 108: $1-84$.

Main, B.Y. (1995). Additional records of the Gondwanan spider Austrarchaea from southwestern Australia. Western Australian Naturalist 20: 151-154.

Platnick, N.I. (1991). On Western Australian Austrarchaea (Araneae, Archaeidae). Bulletin of the British Arachnological Society 8: 259-261.

Manuscript received 21 May 2001; accepted 15 August 2001. 